\title{
Vertical movements of North Sea cod
}

\author{
Victoria J. Hobson ${ }^{1,2, *}$, David Righton ${ }^{2}$, Julian D. Metcalfe ${ }^{2}$, Graeme C. Hays ${ }^{1}$ \\ ${ }^{1}$ Department of Biological Sciences, Institute of Environmental Sustainability, Swansea University, Singleton Park, \\ Swansea SA2 8PP, UK \\ ${ }^{2}$ Centre for Environment, Fisheries and Aquaculture Science, Lowestoft Laboratory, Pakefield Road, Lowestoft, \\ Suffolk NR33 0HT, UK
}

\begin{abstract}
Various air-breathing marine vertebrates such as seals, turtles and seabirds show distinct patterns of diving behaviour. For fish, the distinction between different vertical behaviours is often less clear-cut, as there are no surface intervals to differentiate between dives. Using data from acoustic tags $(n=23)$ and archival depth recorders attached to cod Gadus morhua $(n=92)$ in the southern North Sea, we developed a quantitative method of classifying vertical movements in order to facilitate an objective comparison of the behaviour of different individuals. This method expands the utilisation of data from data storage tags, with the potential for a better understanding of fish behaviour and enhanced individual based behaviour for improved ecosystem modelling. We found that cod were closely associated with the seabed for $90 \%$ of the time, although they showed distinct seasonal and spatial patterns in behaviour. For example, cod tagged in the southern North Sea exhibited high rates of vertical movement in spring and autumn that were probably associated with migration, while the vertical movements of resident cod in other areas were much less extensive and were probably related to foraging or spawning behaviours. The full reasons underlying spatial and temporal behavioural plasticity by cod in the North Sea warrant further investigation.
\end{abstract}

KEY WORDS: Time-depth recorder · Vertical movement $\cdot$ Satellite tracking $\cdot$ Tuna $\cdot$ Shark $\cdot$ Turtle Resale or republication not permitted without written consent of the publisher

\section{INTRODUCTION}

The way in which animals move through their environment forms a fundamental component of their ecology and, consequently, there have been efforts to understand animal movements over a range of spatial and temporal scales (Carey et al. 1971, Block 2005). In a marine context, vertical movements often play an important role for a range of animals (Hays 2003, Block 2005, Sims et al. 2006). For example, many members of the zooplankton undergo regular diel vertical movements (generally deeper during the day and shallower at night), often seemingly as a predator evasion mechanism (Hays 2003). Similarly, vertical movements are also important for a range of marine vertebrates. Airbreathing marine vertebrates (Hays 2003) must come to the surface to breathe and so their vertical movements (manifested as dives away from the sea surface) occur regularly in association with foraging (Wilson et al. 2002), predator evasion (Heithaus \& Frid 2003) or resting (Schreer et al. 2001). Over the last 20 yr, electronic data-loggers and transmitters have revealed the intricacies of these vertical movements and how they vary temporally and spatially. For example, whales, seals, turtles and sharks commonly have diel patterns of resting and foraging (Schreer et al. 2001), with dive depth often varying in association with vertical movements of their prey (Sims et al. 2006). Similarly, these groups all show different behaviours during migration, where horizontal travel rather than foraging may be the central objective, and may also show marked spatial patterns in diving (Hays et al. 2006).

Vertical movements have also been documented in a wide range of fish species. For example, Carey et al. (1971) described the results of deployments of acoustic transmitters that revealed the vertical movements of large pelagic fish such as bluefin tuna Thunnus sp., broadbill swordfish Xiphias gladius and the great 
white shark Carcharodon carcharias. Metcalfe et al. (1990) and Arnold et al. (1994) used acoustic transmitters to describe the vertical movements of plaice Pleuronectes platessa and cod Gadus morhua. The prohibitive expense of acoustic tracking of fish on a large scale has led to the development of relatively inexpensive electronic data storage tags (DSTs). While these need to be physically returned for data download, DSTs have been deployed in large numbers on a variety of fish species (Hunter et al. 2004, 2006, Block 2005, Righton et al. 2006, Sims et al. 2006), particularly those that are commercially exploited, to reveal details of their habitat utilisation, confirming the large scale movements of migratory fish (Block 2005).

As with air-breathing vertebrates, patterns of vertical movements in fish have been most often associated with foraging and migration. For example, Metcalfe \& Arnold (1997) described a characteristic pattern of selective tidal stream transport of a plaice that migrated between spawning and feeding grounds in the North Sea. Hunter et al. (2004) later detailed the vertical movements of plaice in the southern North Sea and revealed complex tidal, diel and lunar rhythms in the extent and timing of vertical movements. Nichol \& Somerton (2002) related the diel vertical movements of Atka mackerel Pleurogrammus monopterygius to foraging and spawning behaviour. Musyl et al. (2003) have described extensive vertical migrations of pelagic fish species such as big eye tuna Thunnus obesus. These vertical movements have been related to foraging on prey within the deep scattering layer (Holland et al. 1999); this behaviour appears common in other tuna species, such as southern bluefin tuna Thunnus maccoyii (Davis \& Stanley 2002). In addition, some vertical movements seem associated with behavioural thermoregulation at the sea surface (Carey et al. 1971).

Cod Gadus morhua are currently a species of particular concern with respect to fishery management, given recent rapid declines in certain stocks, such as cod on the Grand Banks (Myers et al. 1997) or from the North Sea (Christensen et al. 2003). Over recent years there has been considerable effort to understand the behaviour of individual cod, for example in Newfoundland (Rose et al. 1995), Iceland (Palsson \& Throsteinsson 2003), Barents Sea (Stensholt 2001) and the North and Irish Seas (Righton et al. 2001, Neat et al. 2006). As a step towards achieving this goal, we describe the use of acoustic and DSTs to identify the vertical movements of cod tagged at a range of sites in the North Sea. We set out to assess the dominant patterns of depth utilisation with respect to the surface and the seabed, to objectively classify behaviour types and to quantify temporal and spatial changes in behaviour in an efficient and automated manner.

\section{MATERIALS AND METHODS}

Acoustic tracking. Tracking experiments using cod tagged with acoustic transmitters were conducted in 1976. Full details of fish capture, tag attachment and tracking can be found in Arnold et al. (1994). In brief, 24 cod were caught on rod and line just off the shore off Lowestoft, UK $\left(52.77^{\circ} \mathrm{N}, 1.35^{\circ} \mathrm{E}\right)$ (Fig. 1) at a maximum depth of $8 \mathrm{~m}$ and brought to the surface slowly to prevent damage to the swimbladder. The cod were then fitted with $300 \mathrm{kHz}$ transmitting acoustic tags and returned to the seabed in a holding cage to allow them to readapt to ambient pressure over the next 12 to $149 \mathrm{~h}$. On release from the cage, estimates of the depth of the fish and seabed were made by elevation scanning using a sector scanning sonar (Greer Walker et al. 1978) at intervals of 5 min or less (unless the fish was on the seabed, in which case values were estimated approximately every $15 \mathrm{~min}$ ) for periods of up to $48 \mathrm{~h}$. The estimate of depth was subject to an error of $\pm 3 \mathrm{~m}$ at the mean tracking range of $175 \mathrm{~m}$. When cod were in midwater, we calculated distance from the seabed as the difference between the measured depth of the tag and the measured depth of the seabed.

Data storage tags. In total, $665 \mathrm{cod}$ in 21 batches were tagged with electronic DSTs between March 1999 and January 2006. The area of release was bounded by the coordinates $50^{\circ} \mathrm{N}, 3^{\circ} \mathrm{W}$ to $60^{\circ} \mathrm{N}, 6^{\circ} \mathrm{E}$ (Fig. 1). Tagged cod were released in 5 general loca-

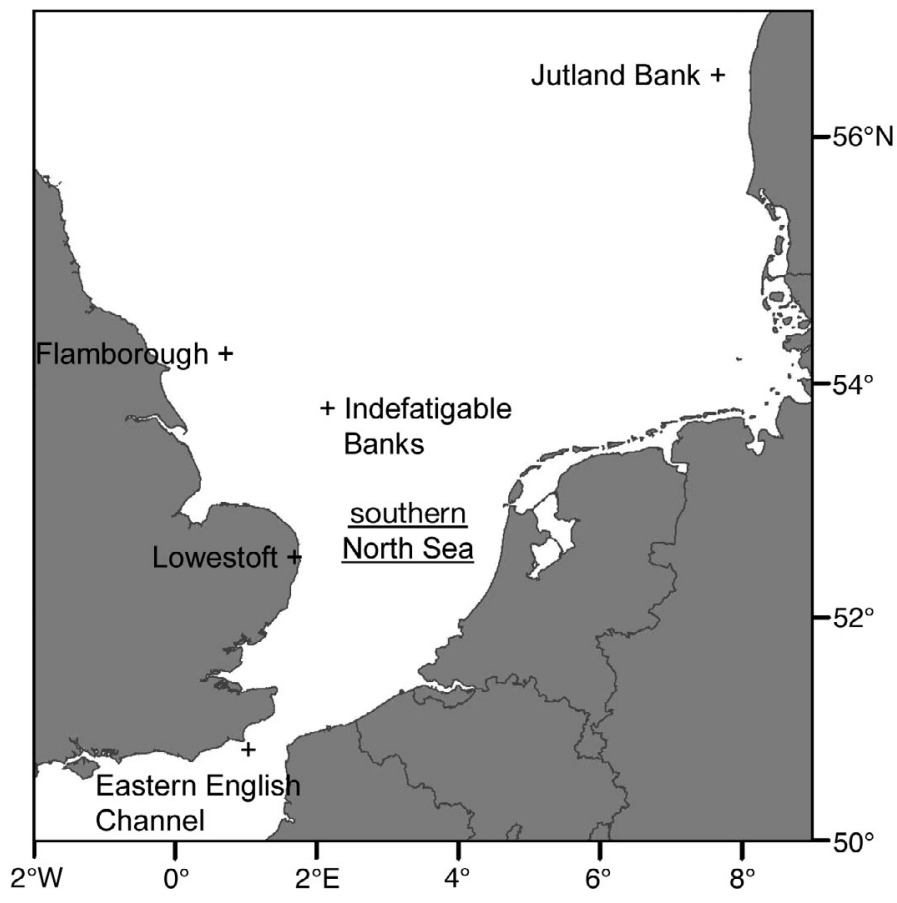

Fig. 1. Southern North Sea, showing the regions (+) where tagged cod were released 
tions: off Lowestoft (LWT; 279 DSTs), on a feeding ground (the Indefatigable Banks) in the southern North Sea (IFB; 49 DSTs), off the northeastern coast of England at Flamborough (FLA; 54 DSTs), on the Jutland Bank (JUT; 100 DSTs), and in the eastern English Channel (CHA; 183 DSTs).

We fitted several different types of DSTs to cod depending upon the size of the individuals (mean length of $\mathrm{cod}=56 \mathrm{~cm}, \mathrm{SD}=9 \mathrm{~cm}$ ) or the attachment method. The makes used were Lotek (LTD1200 [279 used] and LTD1400 [105]; Lotek Marine Technologies), Star-Oddi (Milli [27], Centi [223]; Star-Oddi Marine Device Manufacturing), and CEFAS Technology (G5 [28]; Cefas Technology). The DSTs were attached either externally or internally, as described in Neat et al. (2006) and Righton et al. (2006). DSTs were programmed to collect pressure and temperature every 10 or $20 \mathrm{~min}$ during the period of liberty. Depth was measured with a precision of at least $0.02 \mathrm{~m}$ depending on the type of DST. Sensor drift was determined by comparing the surface values at the start and end of deployments. Drift was low (mean $=0.37 \mathrm{~m}$ per $100 \mathrm{~d}, \mathrm{n}=31 \mathrm{DST}$ still recording at the time of recovery) and so did not affect our data analysis. DSTs were returned to Cefas, Lowestaft Laboratory, from the commercial fishery via a reward scheme. On return to the laboratory, the DSTs were downloaded and the data archived. Measurements made at $20 \mathrm{~min}$ intervals were then interpolated to $10 \mathrm{~min}$ intervals to provide the same temporal sampling for each individual. At the time of writing, 130 DSTs have been returned (Table 1). We then selected the records of more than 1 mo duration from each area of release for a more detailed analysis of vertical movement behaviour. The length of each data record was highly variable (mean $=120 \mathrm{~d}$ at liberty, $\mathrm{SD}=110 \mathrm{~d}$ at liberty). The number of days available for analysis was not distributed evenly across the seasons (mean $\mathrm{d} \mathrm{mo}^{-1}=1050, \mathrm{SD}=435 \mathrm{~d}$ ); the number of days used in analysis showed a binomial distribution, peaking in April (1924 d), and December
(1536 d), and declining to a minimum of $542 \mathrm{~d}$ in October. Temperature measurements were not used in this study.

Data exclusion. The majority of cod showed a period of re-acclimatisation to their capture depth immediately after release, a consequence of the re-inflation of the swimbladder after its rupture or emptying during the capture process (Nichol \& Chilton 2006). The duration of this post-tagging behaviour is variable, but typically lasts no longer than $7 \mathrm{~d}$, after which normal behaviour resumes. This behaviour was not observed in the depth records of cod tagged with acoustic transmitters because they were re-acclimatised before tracking began. It was, however, observed frequently in the depth series of cod fitted with DSTs, which were not re-acclimatised before release. We therefore excluded the first $14 \mathrm{~d}$ from the start of the depth series to avoid including this artefact in our analyses. In addition, we excluded the data from the day of recapture to avoid including behaviour or depth changes related to capture.

\section{RESULTS}

\section{Acoustic tracking}

Analysis of the acoustic data showed that cod spent a large proportion of their time in midwater, with individuals visiting the seabed (Fig. 2) at regular intervals (mean $2.07 \mathrm{~h}, \mathrm{SD}=3.25 \mathrm{~h}$ ), with a modal interval of $1 \mathrm{~h}$, and a maximum interval of $20 \mathrm{~h}$. The regular frequency of these visits to the seabed suggests that seabed depth can be inferred using data from DSTs; the relationship of the maximum depth fish tracked acoustically $(n=23)$ recorded per day and the concurrent seabed depth recorded was highly significant $\left(\mathrm{r}^{2}=\right.$ 0.99, $\mathrm{p}<0.0001)$. Mean depth of individuals ranged between 4.6 and $42.3 \mathrm{~m}$, with a standard deviation of $8.78 \mathrm{~m}$. Mean distance from the seabed ranged between 1.4 and $31.9 \mathrm{~m} \mathrm{~d}^{-1}$, with a maximum of

Table 1. Summary statistics for the number of data storage tags (DSTs) deployed on cod in each area (see Fig. 1). Data from the DSTs released in Lowestoft and on the Indefatigable Banks were combined for the analysis, due to their close geographic locations

\begin{tabular}{|c|c|c|c|c|c|c|}
\hline Population & $\begin{array}{l}\text { Release } \\
\text { location }\end{array}$ & $\begin{array}{l}\text { No. of fish } \\
\text { released }\end{array}$ & $\begin{array}{l}\text { No. of tags } \\
\text { returned }\end{array}$ & $\begin{array}{c}\text { No. of tags } \\
>30 \mathrm{~d}\end{array}$ & $\begin{array}{l}\text { Days at } \\
\text { liberty }\end{array}$ & $\begin{array}{l}\text { Longest } \\
\text { record (d) }\end{array}$ \\
\hline Flamborough & $54.51^{\circ} \mathrm{N}, 0.18^{\circ} \mathrm{E}$ & 54 & 10 & 9 & 1002 & 138 \\
\hline Eastern Channel & $50.87^{\circ} \mathrm{N}, 0.74^{\circ} \mathrm{E}$ & 183 & 40 & 30 & 3597 & 456 \\
\hline Indefatigable Banks & $53.40^{\circ} \mathrm{N}, 2.11^{\circ} \mathrm{E}$ & 49 & 11 & 5 & 958 & 449 \\
\hline Jutland Bank & $56.68^{\circ} \mathrm{N}, 7.30^{\circ} \mathrm{E}$ & 100 & 6 & 6 & 1925 & 540 \\
\hline Lowestoft & $52.45^{\circ} \mathrm{N}, 1.83^{\circ} \mathrm{E}$ & 279 & 63 & 42 & 3525 & 449 \\
\hline Total & & 665 & 130 & 92 & 11007 & \\
\hline
\end{tabular}


$47 \mathrm{~m}$. The errors associated with the estimated depth measurements of the fish and the seabed are discussed by Arnold et al. (1994).

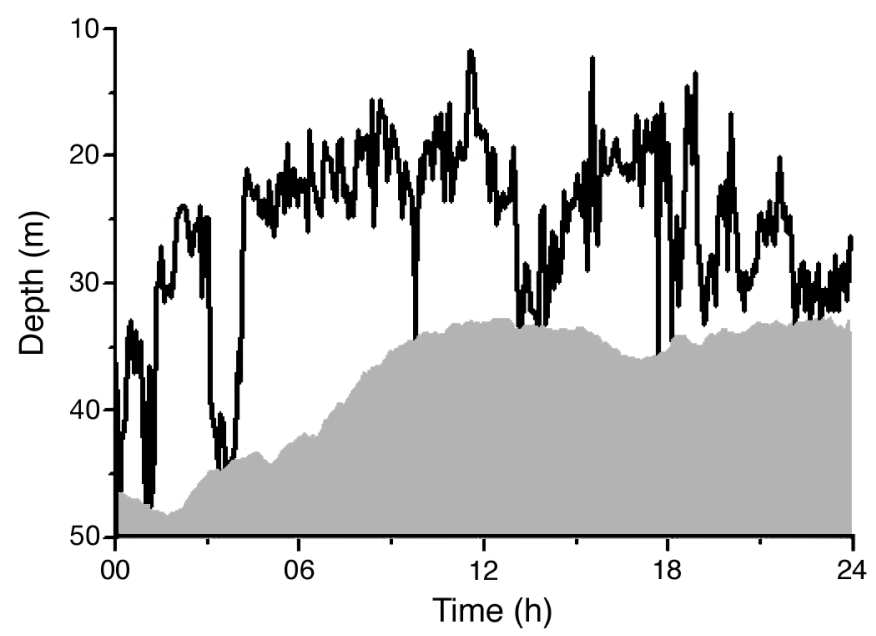

Fig. 2. Gadus morhua. Example data recorded from a fish using an acoustic tag, with simultaneous seabed measurement, showing regular seabed visits
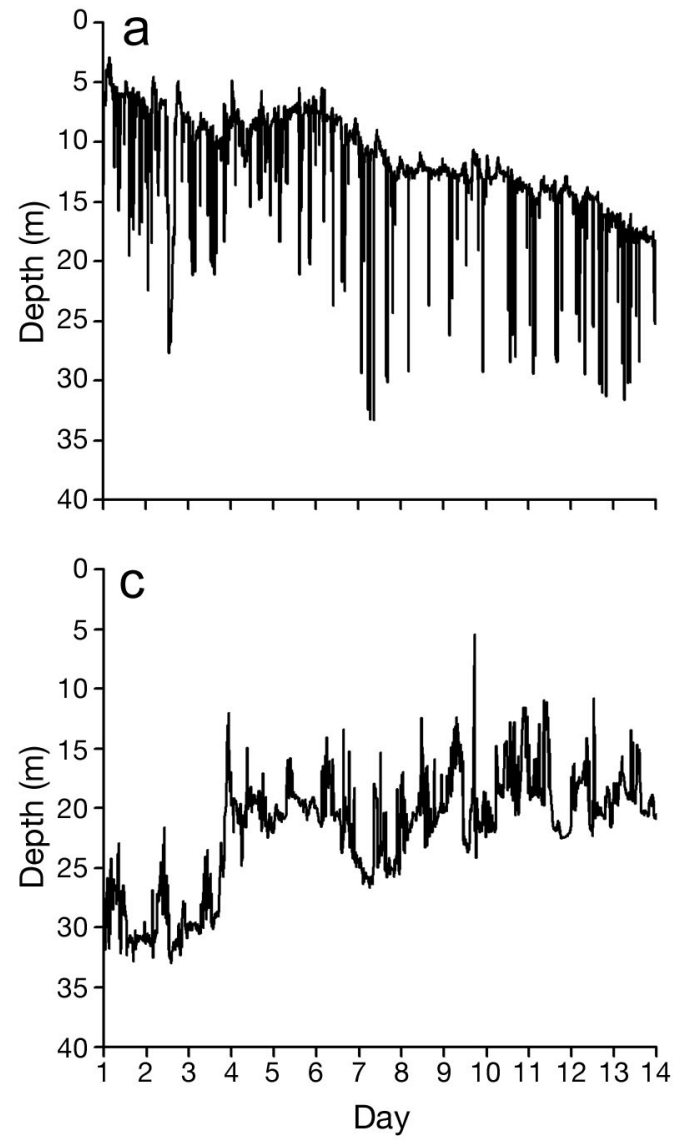

\section{DST data}

Visual inspection of depth time-series from the DST data indicated that cod showed a variety of behaviours throughout their time at liberty. Large descents towards the seabed away from the median depth were described by $4.3 \%$ of the days (Fig. 3a). For $5.7 \%$ of the days, cod maintained a steady mean depth above the seabed and made continuous ascents into midwater or descents towards the seabed (Fig. 3b). On $21.1 \%$ of the days analysed, depth data showed ascents away from the seabed. The position of the fish at a fairly static depth near or on the seabed and the rise and fall of the tide could be seen, interspersed with intermittent vertical ascents into the water column of varying magnitude to shallower water (Fig. 3c). Finally, for the majority of days analysed (68.9\%), the cod appeared to be either on or very close to the seabed, as the depth series showed the continuous rise and fall of a tidal wave above the cod (Fig. 3d). These different behaviour types were described as midwater (MW), continuous search (CS), seabed with ascents (SW); seabed with ascents) and seabed (SB).
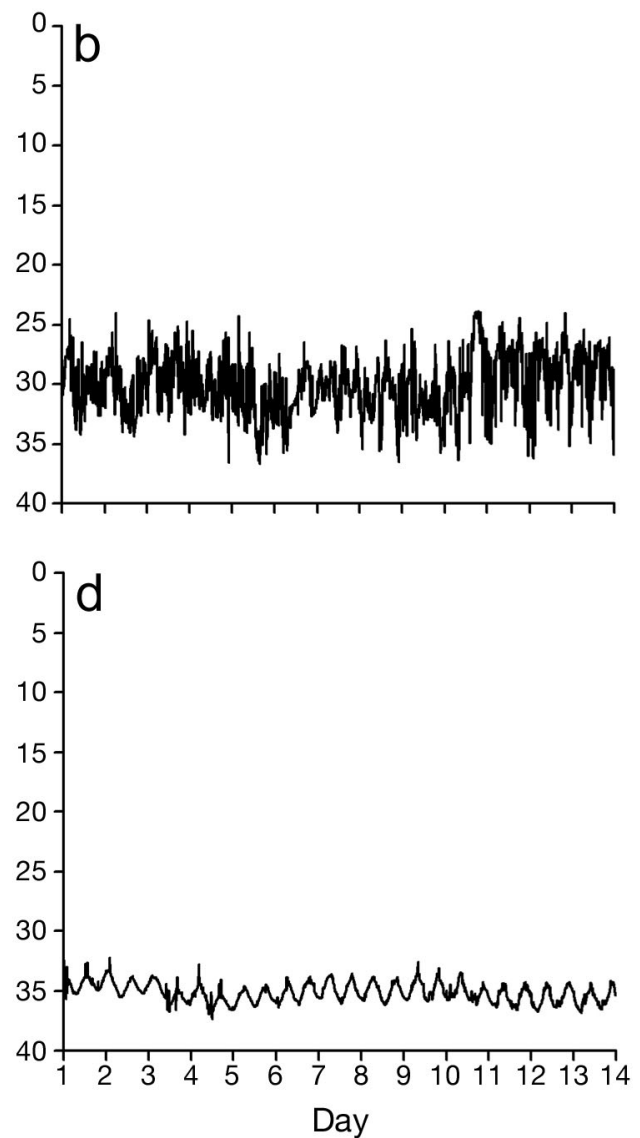

Fig. 3. Gadus morhua. Examples of the 4 different general behaviour types identified by eye: (a) midwater (MW), (b) continuous search (CS), (c) seabed with ascents (SW) and (d) seabed (SB) 
To develop an objective method of defining these behavioural types, examples of each type were first identified by eye. From the subset of DSTs (number of days at liberty $>1 \mathrm{mo}$ ), we selected 1 tag from each of 4 tagging locales and classified each day's behaviour by eye ( $600 \mathrm{~d}$ of data in total). Next, for each section of data corresponding to a single behavioural type being performed for at least $1 \mathrm{~d}, 2$ values were calculated. First, the skew of the frequency distribution for the depth values was determined using the SKEW function in the $\mathrm{R}$ software package ( $\mathrm{R}$ Development Core Team 2004):

$$
\text { Skew }=\frac{n}{(n-1)(n-2)} \sum\left(\frac{x_{j}-\bar{x}}{s}\right)^{3}
$$

where $\bar{X}$ is the sample mean and $s$ is the standard deviation. This skew distinguished between movements dominated by descents to the seabed (depth values positively skewed) or ascents into midwater (negatively skewed) (Fig. 4b). Second, the difference between the median and maximum depths ( $\left.D_{\text {md-max }}\right)$ was calculated. $D_{\text {md-max }}$ reflects whether the fish was close to the seabed or at some distance from it (Fig. 4c). By combining these 2 factors, we were able to accurately classify the type of behaviour each day in the vast majority of cases using just the skew and $D_{\text {md-max }}$ values $(\mathrm{MW}=96 \%, \mathrm{CS}=97 \%, \mathrm{SW}=95 \%, \mathrm{SB}=100 \%)$ (Fig. 4d). Thresholds for these factors were determined by eye using Fig. 4b,c; where distinct differences could be seen between the different behaviours identified, threshold values for the 4 behaviours were determined: $\mathrm{MW}$ (skew $\left.=1, D_{\text {md-max }}>10\right), \mathrm{CS}(-1 \leq$ skew $<1$, $D_{\text {md-max }}>10$ ), SW (skew $=-1, D_{\text {md-max }}<10$ ) and SB $\left(-1 \leq\right.$ skew $\left.<1, D_{\text {md-max }}<10\right)$.

In order to determine where the fish is in the water column (i.e. demersal or pelagic) the depth of the seabed was required. When the cod were very close to or on the seabed (SB or SW), the data logger recorded a clear sine wave as the water depth changed over the course of the tidal cycle (Righton et al. 2001, Nichol \& Chilton 2006); in these cases, seabed depth was calculated as the mean depth in any $24 \mathrm{~h}$ period. When cod were in midwater (MW or CS), we used the assumption, deduced from the acoustic data, that their descents were to the seabed and that the maximum depth in any $24 \mathrm{~h}$ period was likely to correspond to the seabed depth. These values were then interpolated (Fig. 5) to the temporal resolution of the tag using a $24 \mathrm{~h}$ moving window, where the maximum depth from $12 \mathrm{~h}$ on either side of the depth measurement has been taken and moves along to estimate seabed depth ( $\mathrm{SE}=$ 0.18). Distance from the seabed was then calculated for each depth measurement for each day.

In total, 92 cod data sets yielded $11007 \mathrm{~d}$ of data for analysis. The mean depth of individuals ranged
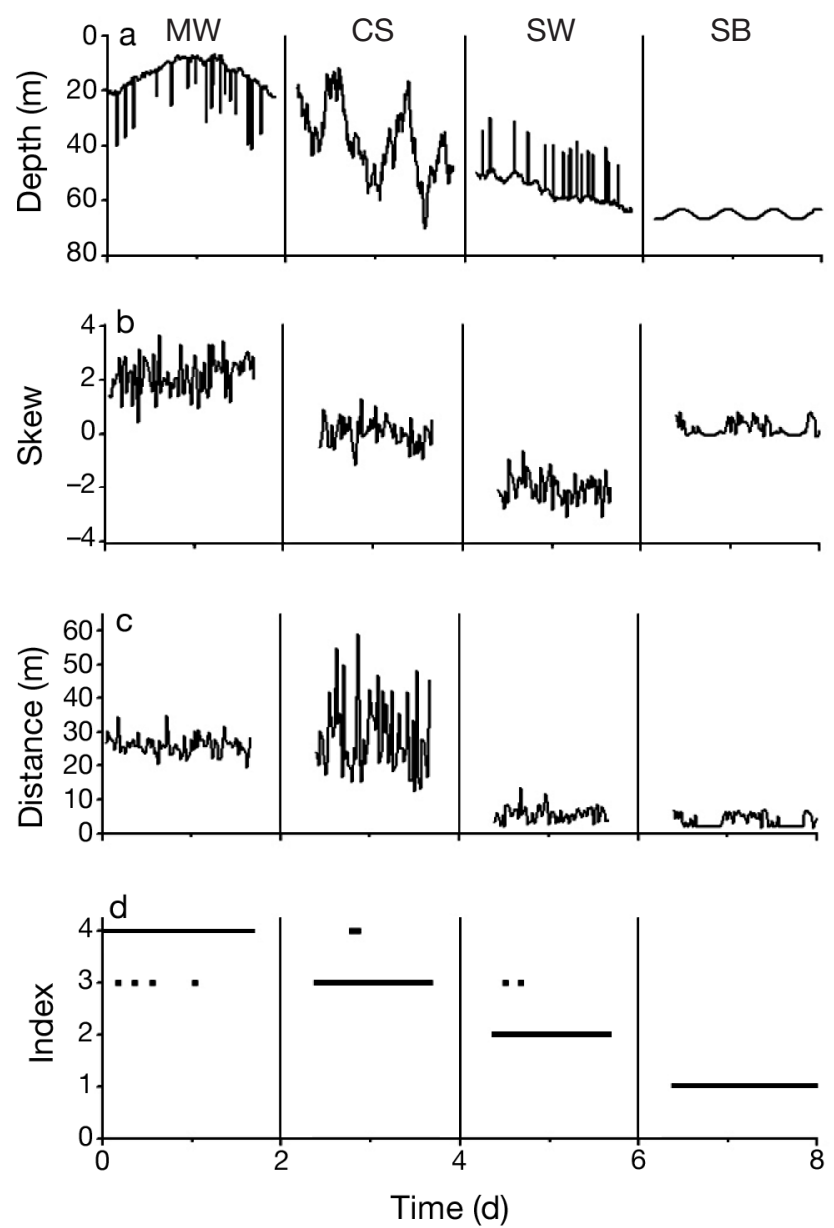

Fig. 4. Stages of the objective methodology used to classify the daily behaviour of the cod from DSTs. (a) Example depth records of the different behaviour types, amalgamated from several data records. (b) The corresponding skew value for each behaviour example in (a). (c) The corresponding median - maximum depth value for the day. (d) The resulting index using the classification method showing the different behaviour types: midwater (MW), continuous search (CS), seabed with ascents (SW) and seabed (SB)

between 7.95 and $104.6 \mathrm{~m}$ with a standard deviation of $18.7 \mathrm{~m}$. Mean distance from the seabed ranged between 0.1 and $35.8 \mathrm{~m} \mathrm{~d}^{-1}$, with values at any one time reaching up to $67.9 \mathrm{~m}$. The predominant form of behaviour across all areas was SB (Fig. 6), accounting for $70 \%$ of the behaviour each month (SD $=0.05 \%$ ), with $20.5 \%(\mathrm{SD}=0.03 \%$ ) attributed to behaviour also associated with the seabed (SW).

Cod tagged in the southern North Sea (Fig. 7a) were the most active cod in this study in terms of their vertical movement. They exhibited great seasonal variability in vertical movement, with distinct periods when they were found high in the water column, either continuously searching or referencing the seabed. These 2 behaviours account for more than $25 \%$ of their behav- 


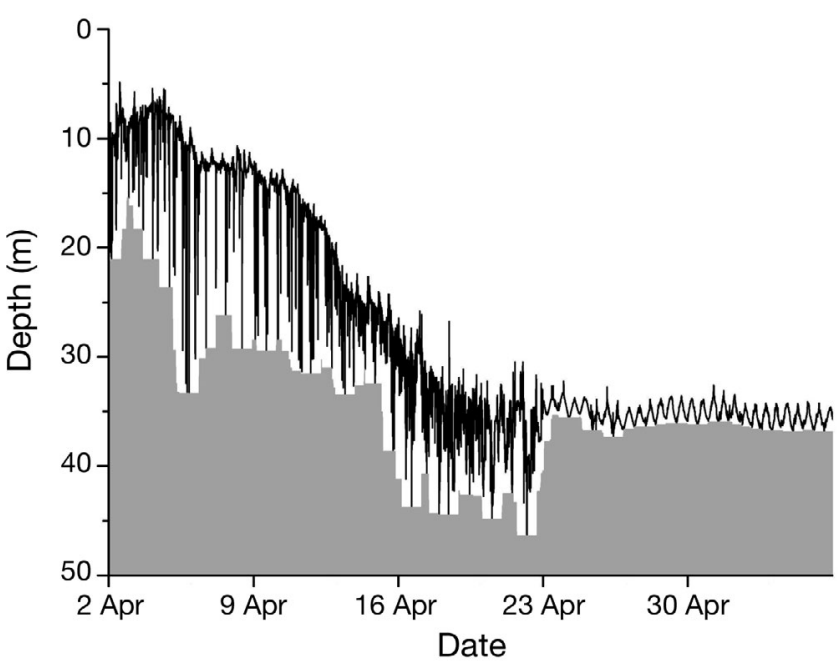

Fig. 5. Gadus morhua. Depth profile from a fish tagged near Lowestoft in 1999, showing the interpolation of the seabed (solid grey) using the maximum recorded depth of the fish per day

iour in the months from November to March. The rest of the year the cod from this region showed a strong association with the seabed, and from May to September they spent more than $95 \%$ of their time very close to the seabed. Cod tagged off the Danish coast on the Jutland Bank (Fig. 7b) showed limited activity throughout the year. They spent $63.9 \%$ of their time at the seabed, and $35.9 \%$ was associated with the seabed with frequent ascents away from it. Only $0.2 \%$ of the Jutland fishes' time could be attributed to midwater behaviour.

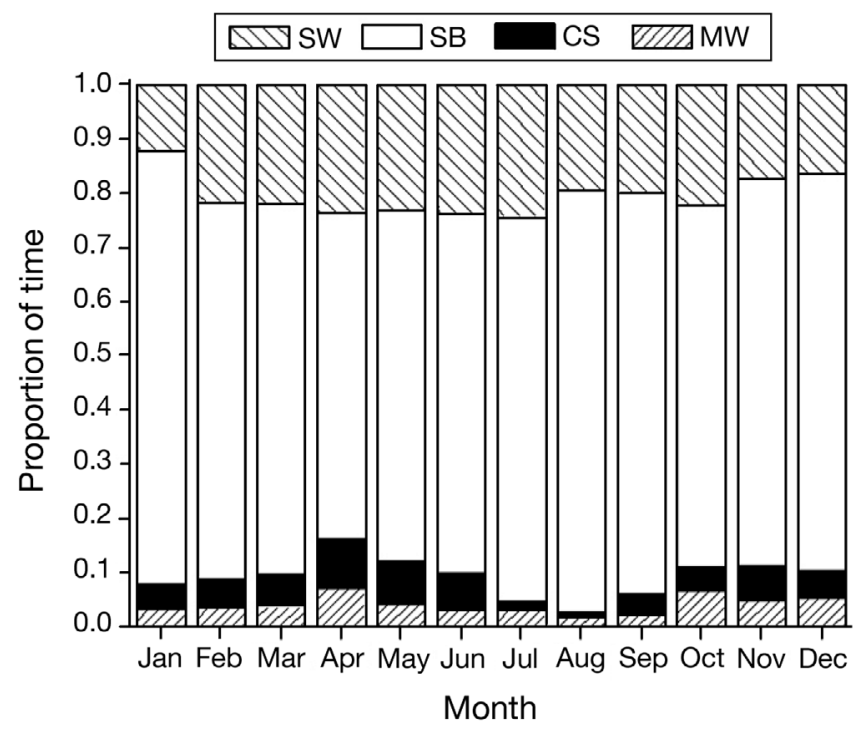

Fig. 6. Gadus morhua. Proportion of time spent by southern North Sea cod $(\mathrm{n}=92)$ in each of the 4 classified behaviours: midwater (MW), continuous search (CS), seabed with ascents (SW) and seabed (SB). Seasonal distribution of behaviour over the course of a year
The behaviour of cod tagged close to Flamborough (Fig. 7c) and in the eastern English Channel (Fig. 7d) showed similar patterns of vertical movement. Analysis of the proportion of behaviour types shows that the majority of their time was spent close to the seabed $(\mathrm{FLA}=78 \%, \mathrm{CHA}=80.7 \%)$ with an extra $17 \%(\mathrm{FLA})$ or $11.8 \%$ (CHA) of the time spent on the seabed making occasional movements into the water column. The fish spent only $5 \%$ (FLA) and $7.5 \%$ (CHA) of the time recorded in midwater. Across all areas, over $55 \%$ of their time was spent within $5 \mathrm{~m}$ of the seabed (Fig. 8).

\section{DISCUSSION}

Warming sea temperatures associated with global climate change could lead to the loss of cod stocks from the North Sea and to the associated socio-economic implications (Christensen et al. 2003). Knowledge of the vertical movements of fish allows an improved understanding of the implications of their vulnerability and accessibility to trawls and surveys (Aglen et al. 1999, Godo \& Michalsen 2000), allowing for improved stock estimates. In addition, understanding the vertical movements can enhance our understanding of survey data of conventional fisheries (Aglen et al. 1999).

A key step in this study was the development of an objective method for classifying cod behaviour based on their vertical movements. Objective methods for defining the vertical movements of marine vertebrates have been previously documented in studies of seals, turtles and seabirds (Hochscheid \& Wilson 1999, Schreer et al. 2001), but to date, the analysis of vertical movement data for fish has been largely descriptive (e.g. Godo \& Michalsen 2000, Righton et al. 2001). An exception is the recent use of spectral analysis for distinguishing between normal and reverse diel vertical migration in planktivorous sharks (Graham et al. 2006). Various methods for classifying dives for airbreathing vertebrates have been used, often involving multi-variant techniques that summarise the duration, depth and shape of dive profiles (Schreer et al. 2001). Each dive type is used to infer a different dive function or outcome (Schreer et al. 2001), such as prey searching, prey capture or sleeping. However, defining the start and the end of a dive for air-breathing vertebrates is relatively straightforward since each dive starts and ends with the animal breathing at the surface. Defining the start of 'dives' for fish species is more problematic because the movements of many fish have no obvious start or end points, even though they may be broadly classed as demersal or pelagic (Godo \& Michalsen 2000, Nichol \& Chilton 2006). We therefore used an approach of defining the 'behavioural state' of each fish on a day-by-day basis rather than attempting 

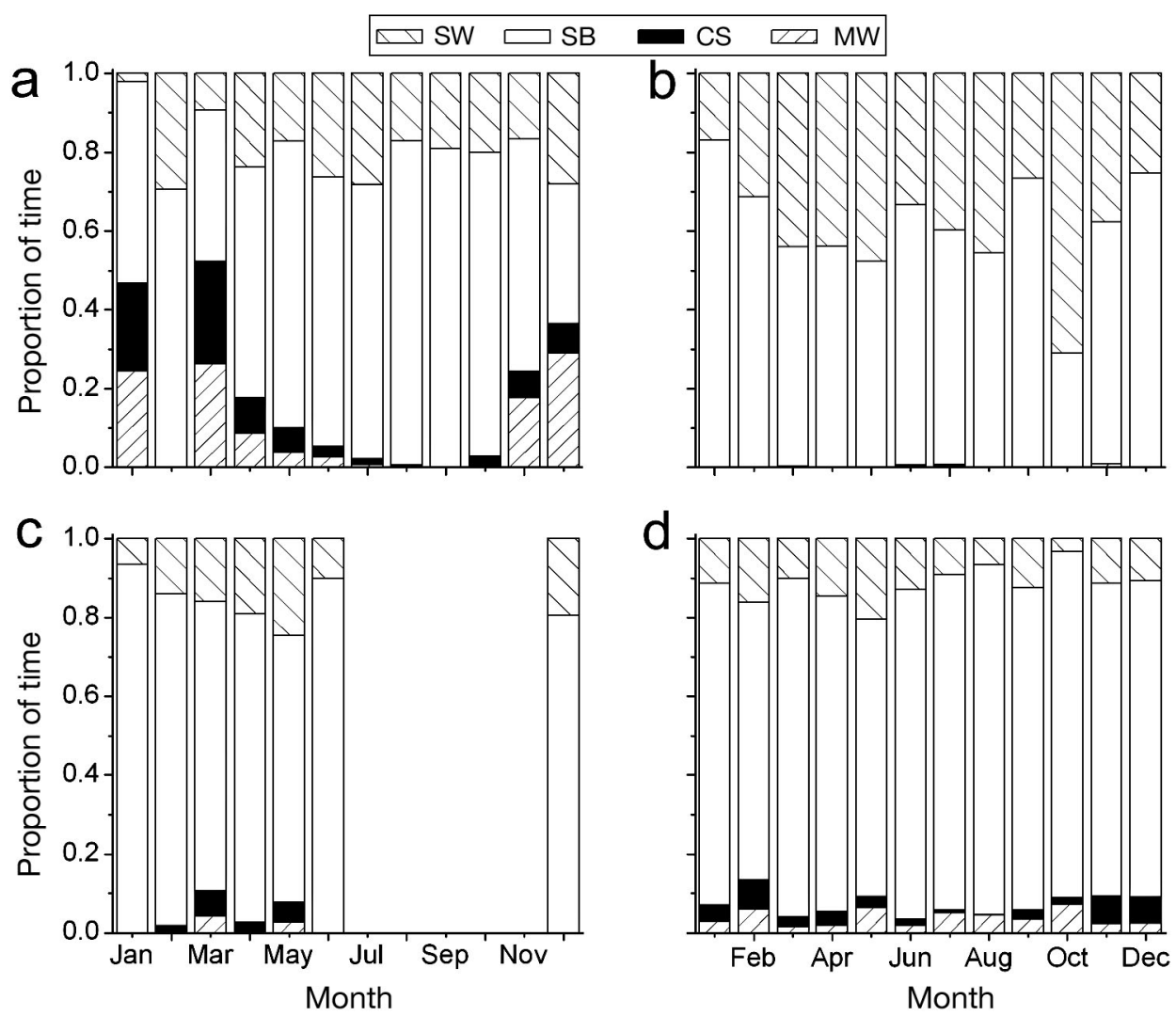

Fig. 7. Gadus morhua. Proportion of time spent by southern North Sea cod in each of the 4 classified behaviours - midwater (MW), continuous search (CS), seabed with ascents (SW) and seabed (SB) - for fish tagged in (a) the southern North Sea, (b) Jutland Bank, (c) Flamborough, (d) the eastern English Channel

to define when an individual behaviour started or ended. Our approach of using simple explanatory statistics (skew and range of median: maximum depth per day) seems robust in that it corroborated the behavioural type identified by eye in $97 \%$ of occasions.

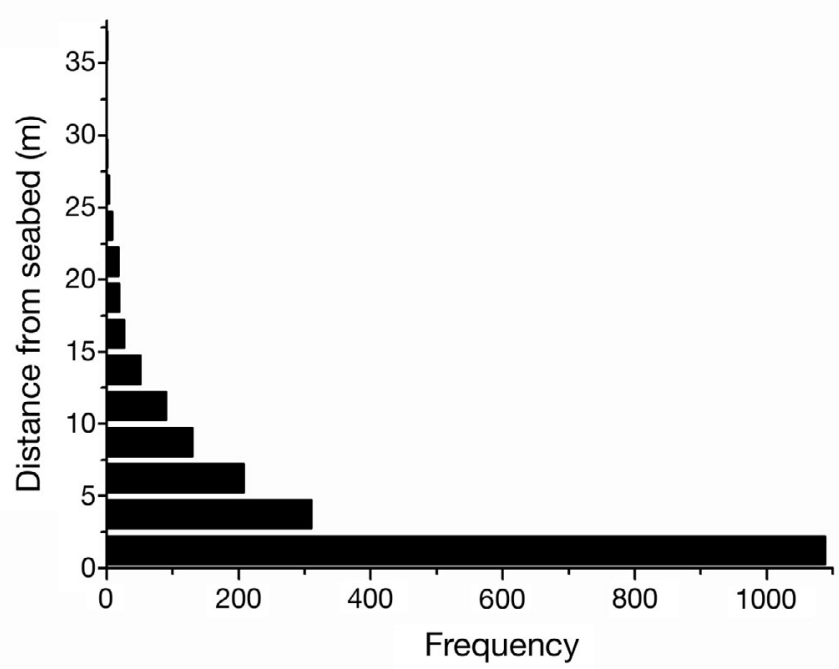

Fig. 8. Gadus morhua. Frequency histogram representing the proportion of time cod fitted with DSTs spent at various distances from the seabed
Hence, we have created a methodology that enables the dominant behaviour of a fish to be quickly and objectively defined on a daily basis. Given the huge number of data-storage tags currently being employed in various studies with fish (Brill et al. 2002), this approach may have wide utility, particularly for demersal fish or those which are known to utilise the whole water column, such as sharks, where the sea surface could be used as a reference point.

Central to our interpretation of DST data was the axiom that cod regularly visit the seafloor. The development of this axiom through simultaneous measurement of the depth of the fish and seabed depth using acoustic tracking was therefore central to our work. While direct acoustic tracking from boats is used relatively seldom nowadays compared to the use of DSTs and satellite tags, the approach clearly remains important in being able to reveal detailed aspects of an animal's immediate environment (e.g. seabed depth) not revealed by other approaches. Having established that cod regularly visit the seabed, we were then able to make far more use of the much larger data sets collected with DSTs. There may be long-term changes in fish behaviour in the North Sea due to fishing pressures (Conover \& Munch 2002); the behaviour dis- 
played by fish fitted with DSTs may represent the successful behavioural characteristics needed to survive intense fishing efforts. The acoustic data from 1976 is used here to validate vertical movements of cod and confirm their association with the seabed; however, the extent of behavioural association with the seabed in the acoustically tagged fish is unknown and may have changed over time.

The function of the 4 behavioural types we identified remains speculative. One of the behavioural states (SB) seems to indicate general inactivity by the fish, with almost no vertical excursions, although we cannot exclude the possibility that cod were moving horizontally across a flat seabed. This depth signal has also been noted in tags attached to plaice (Hunter et al. 2004) and thornback rays in the North Sea (Hunter et al. 2006). The other 3 behavioural states (CS, MW, and SW) show greater vertical movement, implying greater foraging activity. The marked vertical excursions seen in midwater were mostly observed in autumn and spring and were associated with frequent changes in seabed depth (Fig. 5) and occasional sudden changes in temperature. These facts indicate that the individuals move between different locales during post- or prespawning migrations, and the vertical movements may reflect a foraging or search strategy used by cod as they transit through unfamiliar locations. Such behaviour has also been described for some other fish species. For example, Brill et al. (2002) used acoustic tracking of tuna to show that they make use of the entire water column and make frequent (albeit brief) descents to the seabed. Similar dive-like behaviour has been shown in whale sharks (Gunn et al. 1999). The temporal resolution of the data collection (once every $10 \mathrm{~min}$ ) means it is likely that fine-scale movements and behaviours, such as an excursion to capture prey from the seabed, are not captured. One of the DSTs was pre-programmed to record at a higher resolution (10 s intervals) for $2 \mathrm{wk}$ during July. This data did not show any vertical activity, and the fish was associated with the seabed for the entire period.

The reasons behind the vertical excursions seen in midwater and continuous searching behavioural states are unclear and we can only speculate as to their functions. Physicochemical and biological water characteristics often vary much more quickly in the vertical than in the horizontal dimension. For example, with increasing depth, illumination levels and water temperature generally decrease. Similarly, prey and predators may be concentrated at certain depths. Heithaus et al. (2002) show tiger sharks undertaking 'bouncing' or fast deep dives, followed by a few minutes at depth, then a slow ascent, and suggest that these dives could be a foraging tactic to widen opportunities for catching both pelagic or surface prey and demersal prey by bal- ancing their time in both areas. Holland et al. (1999) describe a depth record of a tiger shark making largescale vertical descents when in the open ocean and suggest that this may be an orientation mechanism that the shark uses to determine if it is moving into or away from shallow water. However, Klimley (1993) suggests that hammerhead sharks move up and down the water column to identify a layer of water with a site-specific olfactant and that the vertical diving oscillations were not restricted to thermal boundaries.

Vertical excursions may therefore serve a 'prospecting' role and allow marine animals to quickly gather information about a wide range of conditions. For example, cod have been observed feeding high in the water column, predominantly at night when pelagic prey are available there (Strand et al. 2005). However, during the day, occasional steep ascents may be performed as if cod are prospecting to see if their prey are still in that area and so might be encountered on the subsequent night (Godo \& Michalsen 2000).

To distinguish between these possibilities, a useful measurement parameter would be the rate of feeding associated with each behavioural type. Similarly, there are currently major efforts to measure feeding rates associated with dive types for air-breathing vertebrates such as seals (Bowen et al. 2006) and penguins (Wilson et al. 2002) using approaches such as stomach temperature recorders, video imaging, and mouth opening sensors. Until the technology has been further miniaturised to permit the measurement of feeding rate in relatively small vertebrates like cod, our inferences about the purpose of vertical movements will remain educated guesses.

Cod of all size classes are found near the seabed; however, despite being regarded as a demersal fish, the species is known to migrate up the water column (Aglen et al. 1999). The activity of cod is also known to vary over seasonal time periods, as seen in studies of cod in the North and Irish seas (Righton et al. 2001). A key finding of our study was that, when considering the data set as a whole, cod showed a general tendency to be closely associated with the seabed and only $10 \%$ of the overall time was spent in midwater behavioural states. This finding confirms previous work with this species in shallow shelf seas (Righton et al. 2001). In contrast to our results, cod living in deeper water in the Barents Sea and the Icelandic Sea often make large vertical movements to hundreds of metres above the seabed in order to feed on their main prey, capelin (Godo \& Michalsen 2000). In consequence, the migration patterns and habitat use of cod in the Barents Sea closely match those of capelin (Strand et al. 2005). The species can therefore clearly occupy a wide range of depths throughout its range but appears to shape its behaviour to local conditions. For example, 
despite the fairly shallow water depth throughout the North Sea (typically $<100 \mathrm{~m}$ in the central North Sea and $<40 \mathrm{~m}$ in the southern North Sea), cod in different parts of this general area showed markedly different behaviours, and these regional differences were also accompanied by seasonal differences. Inherent in the interpretation of these results is the assumption that the bottom topography of the North Sea is relatively smooth, so the maximum depth in a $24 \mathrm{~h}$ period is fairly constant. In more topographically variable regions, more detailed information about the seabed may be required in order to draw conclusions about water column utilisation.

Our primary aim was to develop an objective method for classifying cod behaviour from depth utilisation data. Clearly, now that the technique has been established, it lends itself to involved statistical analysis of the processes driving the spatio-temporal patterns in cod behaviour, such as time of day, night versus day, tagging location, month tagged and fish size. However, even at this stage some striking patterns are evident. Those cod tagged in the southern North Sea showed far more MW behaviour than those in other areas. The known spawning grounds of cod tagged in the North Sea are found to the south (Metcalfe 2006). Consequently, this occurrence of MW behaviour from November to March may reflect the migration of these fish to their spawning grounds from feeding grounds to the north (Righton et al. 2007) and back again. This period of migration may be a time when cod are particularly susceptible to mortality in fishing nets because they may be away from the shelter of wrecks and other hard substrates, which provides a sanctuary from trawlers. In contrast to the behaviour during the inferred seasonal migration of the fish tagged in the southern North Sea, at other times cod showed very little activity, spending nearly all their time near or on the seabed, with only occasional vertical excursions. This relatively inactive behaviour might reflect the fact that meal sizes for cod can be very large (Adlerstein \& Welleman 2000) and hence animals may feed only occasionally, being quiescent the rest of the time. Alternatively, this inactivity may relate to the high water temperatures in the region, where summer water temperatures can reach around $16^{\circ} \mathrm{C}$ or higher at the seabed. It is likely that water temperature plays a role in the vertical movements of these fish. Clearly, this linkage between water temperature and cod behaviour is something that needs to be explored further, particularly given the concern over increasing water temperatures in the North Sea for the regeneration of cod stocks (Neat et al. 2006). Furthermore, in contrast to the preference of cod in the Barents Sea (Floeter \& Temming 2003) for sprat Sprattus sprattus and herring Clupea harengus, cod in the North Sea have a much more diverse diet (Adlerstein \& Welleman 2000), primarily feeding on molluscs, crustaceans, sandeels Ammodytes spp., haddock Melanogrammus aeglefinus, herring Clupea harrengus, and several flatfish species, which may be associated with the wide behavioural plasticity we noted.

In summary, we have revealed marked differences in the behaviour of cod in different parts of the North Sea, which adds further evidence of behavioural plasticity in support of previous research (Righton et al. 2001, Palsson \& Throsteinsson 2003, Neat et al. 2006). These differences probably, at least partly, reflect the longer seasonal migrations to spawn for fish in certain areas. However, other processes that drive both the regional and seasonal changes in cod behaviour remain enigmatic and warrant further analysis of behavioural types along with associated environmental parameters such as water temperature.

Acknowledgements. We are indebted to many colleagues who contributed to this study and the many skippers and the fishermen who have cooperated with us by helping us to tag cod and also by returning tags. We thank 4 anonymous referees for the constructive criticism of the study. The study was funded by EU project CODYSSEY (Q5RT-2002-00813) and Defra (MF0154), and V.J.H. is supported by a NERC CASE studentship in collaboration with the Centre for Environment, Fisheries and Aquaculture Science, Lowestoft.

\section{LITERATURE CITED}

Adlerstein SA, Welleman HC (2000) Diel variation of stomach contents of North Sea cod (Gadus morhua) during a 24-h fishing survey: an analysis using generalized additive models. Can J Fish Aquat Sci 57:2363-2367

Aglen A, Engås A, Huse I, Michalsen K, Stensholt BK (1999) How vertical fish distribution may affect survey results. ICES J Mar Sci 56:345-360

Arnold GP, Greer Walker M, Emerson LS, Holford BH (1994) Movements of cod (Gadus morhua) in relation to the tidal streams in the southern North Sea. ICES J Mar Sci 51: 207-232

Block BA (2005) Physiological ecology in the 21st century: advancements in biologging science. Integr Comp Biol 45: 305-320

Bowen WD, Iverson SJ, McMillan JI, Boness DJ (2006) Reproductive performance in grey seals: age-related improvement and senescence in a capital breeder. J Anim Ecol 75: 1340-1351

Brill R, Lutcavage M, Metzger G, Bushnell P, Arendt M, Lucy J, Watson C, Foley D (2002) Horizontal and vertical movements of juvenile bluefin tuna (Thunnus thynnus), in relation to oceanographic conditions of the western North Atlantic, determined with ultrasonic telemetry. Fish Bull 100:155-167

Carey FG, Teal JM, Kanwisher JW, Lawson KD, Beckett JS (1971) Warm-bodied fish. Am Zool 11:137-143

Christensen V, Guenette S, Heymans JJ, Walters CJ, Watson R, Zeller D, Pauly D (2003) Hundred-year decline of North Atlantic predatory fishes. Fish Fish 4:1-24

Conover DO, Munch SB (2002) Sustaining fisheries yields 
over evolutionary time scales. Science 297:94-96

Davis TLO, Stanley CA (2002) Vertical and horizontal movements of southern bluefin tuna (Thunnus maccoyii) in the Great Australian Bight observed with ultrasonic telemetry. Fish Bull 100:448-462

Floeter J, Temming A (2003) Explaining diet composition of North Sea cod (Gadus morhua): prey size preference vs. prey availability. Can J Fish Aquat Sci 60:140-150

Godo OR, Michalsen K (2000) Migratory behaviour of northeast Arctic cod, studied by use of data storage tags. Fish Res 48:127-140

Graham RT, Roberts CM, Smart JCR (2006) Diving behaviour of whale sharks in relation to a predictable food pulse. J R Soc Interface 3:109-116

Greer Walker M, Harden Jones FR, Arnold GP (1978) The movements of plaice (Pleuronectes platessa) tracked in the open sea. J Cons Int Explor Mer 38:58-86

Gunn JS, Stevens JD, Davis TLO, Norman BM (1999) Observations on the short-term movements and behaviour of whale sharks (Rhincodon typus) at Ningaloo Reef, Western Australia. Mar Biol 135:553-559

Hays GC (2003) A review of the adaptive significance and ecosystem consequences of zooplankton diel vertical migrations. Hydrobiologia 503:163-170

Hays GC, Hobson VJ, Metcalfe JD, Righton D, Sims DW (2006) Flexible foraging movements of leatherback turtles across the north Atlantic Ocean. Ecology 87:2647-2656

Heithaus MR, Frid A (2003) Optimal diving under the risk of predation. J Theor Biol 223:79-92

Heithaus MR, Dill LM, Marshall GJ, Buhleier B (2002) Habitat use and foraging behavior of tiger sharks (Galeocerdo cuvier) in a seagrass ecosystem. Mar Biol 140:237-248

Hochscheid S, Wilson RP (1999) A new method for the determination of at-sea activity in sea turtles. Mar Ecol Prog Ser 185:293-296

Holland KN, Wetherbee BM, Lowe CG, Meyer CG (1999) Movements of tiger sharks (Galeocerdo cuvier) in coastal Hawaiian waters. Mar Biol 134:665-673

Hunter E, Metcalfe JD, O'Brien CM, Arnold GP, Reynolds JD (2004) Vertical activity patterns of free-swimming adult plaice in the southern North Sea. Mar Ecol Prog Ser 279: 261-273

Hunter E, Berry F, Buckley AA, Stewart C, Metcalfe JD (2006) Seasonal migration of thornback rays and implications for closure management. J Appl Ecol 43:710-720

Klimley AP (1993) Highly directional swimming by scalloped hammerhead sharks, Sphyrna lewini, and subsurface irradiance, temperature, bathymetry, and geomagnetic field. Mar Biol 117:1-22

Metcalfe JD (2006) Fish population structuring in the North Sea: understanding processes and mechanisms from studies of the movements of adults. J Fish Biol 69:48-65

Metcalfe JD, Arnold GP (1997) Tracking fish with electronic tags. Nature 387:665-666

Editorial responsibility: Rory Wilson (Contributing Editor), Swansea, UK
Metcalfe JD, Arnold GP, Webb PW (1990) The energetics of migration by selective tidal stream transport - an analysis for plaice tracked in the southern North Sea. J Mar Biol Assoc UK 70:149-162

Musyl MK, Brill RW, Boggs CH, Curran DS, Kazama TK, Seki MP (2003) Vertical movements of bigeye tuna (Thunnus obesus) associated with islands, buoys, and seamounts near the main Hawaiian Islands from archival tagging data. Fish Oceanogr 12:152-169

Myers RA, Hutchings JA, Barrowman NJ (1997) Why do fish stocks collapse? The example of cod in Atlantic Canada. Ecol Appl 7:91-106

Neat F, Wright P, Zuur A, Gibb I, Gibb F, Tulett D, Righton D, Turner R (2006) Residency and depth movements of a coastal group of Atlantic cod (Gadus morhua). Mar Biol 148:643

Nichol DG, Chilton EA (2006) Recuperation and behaviour of Pacific cod after barotrauma. ICES J Mar Sci 63:83-94

Nichol DG, Somerton DA (2002) Diurnal vertical migration of the Atka mackerel Pleurogrammus monopterygius as shown by archival tags. Mar Ecol Prog Ser 239:193-207

Palsson OK, Throsteinsson V (2003) Migration patterns, ambient temperature, and growth of Icelandic cod (Gadus morhua): evidence from storage tag data. Can J Fish Aquat Sci 60:1409-1423

Righton D, Metcalfe JD, Connolly P (2001) Different behaviour of North and Irish Sea cod. Nature 411:156

Righton D, Kjesbu OS, Metcalfe JD (2006) A field and experimental evaluation of the effect of data storage tags on the growth of cod. J Fish Biol 68:385-400

Righton D, Quayle VA, Hetherington S, Burt G (2007) Movements and distribution of cod (Gadus morhua) in the southern North Sea and English Channel: results from conventional and electronic tagging experiments. J Mar Biol Assoc UK 87:599-613

Rose GA, de Young B, Colbourne E (1995) Cod (Gadus morhua) migration speeds and transport relative to currents on the north-east Newfoundland Shelf. ICES J Mar Sci 52:903-913

Schreer JF, Kovacs KM, Hines RJO (2001) Comparative diving patterns of pinnipeds and seabirds. Ecol Monogr 71:137-162

Sims DW, Wearmouth VJ, Southall EJ, Hill JM and 8 others (2006) Hunt warm, rest cool: bioenergetic strategy underlying diel vertical migration of a benthic shark. J Anim Ecol 75:176-190

Stensholt BK (2001) Cod migration patterns in relation to temperature: analysis of storage tag data. ICES J Mar Sci 58: $770-793$

Strand E, Jorgensen C, Huse G (2005) Modelling buoyancy regulation in fishes with swimbladders: bioenergetics and behaviour. Ecol Model 185:309-327

Wilson RP, Ropert-Coudert Y, Kato A (2002) Rush and grab strategies in foraging marine endotherms: the case for haste in penguins. Anim Behav 63:85-95

Submitted: February 21, 2007; Accepted: May 10, 2007

Proofs received from author(s): September 17, 2007 